\title{
Cidade e Moeda na História: Constantino e Constantinopla, uma nova capital para o Império Romano
}

\author{
City and Coin in History: Constantine and Constantinople, a new capital \\ for the Roman Empire
}

Claudio Umpierre Carlan* Universidade Federal de Alfenas (UNIFAL), Alfenas, MG, Brasil

\begin{abstract}
RESUMO: Neste artigo, realizaremos uma análise iconográfica das representações da Cidade de Constantinopla, fundada pelo Imperador Constantino, como nova capital e rival de Roma, tendo a moeda como documento principal. Tal fundação provocou uma inversão do eixo político, cultural e econômico no mundo mediterrâneo, no qual o Oriente ganha um destaque fundamental, como propagador da cultura greco-romana. Como corpus principal, apresentaremos a coleção numismática do Museu Histórico Nacional, no Rio de Janeiro, importante acervo arqueológico brasileiro, ainda pouco estudado.
\end{abstract}

PALAVRAS-CHAVE: Arqueologia. História. Cidade. Política. Moedas.

ABSTRACT: This article, we will carry out an analysis of the City of Constantinople, founded by Emperor Constantine, as the new capital and rival of Rome. Thus, there was an inversion of the political, cultural and economic axis in the Mediterranean world, in which East gains a fundamental prominence, as propagator of Greco-Roman culture. As a main corpus, we will present the numismatic collection of the National Museum of History, Rio de Janeiro, important archaeological collection Brazilian yet understudied.

KEYWORDS: Archeology. History. City. Politics. Coins.

\footnotetext{
* Professor-Associado da Universidade Federal de Alfenas (UNIFAL), Alfenas, MG, Brasil. Doutor em História pela Universidade Estadual de Campinas (UNICAMP). E-mail: carlanclaudio@gmail.com Orcid: http://orcid. org/0000-0001-9363-8799
} 


\section{Introdução}

Neste artigo, analisaremos apenas as peças monetárias referentes à fundação de Constantinopla, deixando as demais amoedações constantinianas para uma outra oportunidade. É bom ressaltar que tanto as moedas como as medalhas são estudadas pela numismática e, no caso romano, esses símbolos monetários teriam um papel de passar uma mensagem aos governados, em uma espécie de propaganda política/imperial.

Desse todo, 360 moedas e 54 moedas comemorativas foram cunhadas por Constantino ou por sua ordem. Nelas encontramos, na legenda que circunda a peça, o nome e o título imperial.

Caius Flavius Valerius Aurelius Constantinus ou simplesmente Constantino I, o Grande, nasceu em Naissus (Nis) entre 270 e 288, faleceu em Nicomédia no ano de 337. Era filho de Constâncio Cloro, ou Claro, membro da tetrarquia de Diocleciano, e Helena, mais tarde canonizada pela Igreja Católica Romana. Segundo a tradição, em uma peregrinação à Jerusalém, Helena teria encontrado a cruz em que Jesus Cristo fora crucificado. Com isso, é considerada padroeira dos arqueólogos.

Criado na Corte de Diocleciano, na parte Oriental do Império, como refém, caso seu pai não permanecesse fiel ao regime, desde cedo ganhou a admiração dos soldados pelas suas qualidades militares.

A obra religiosa de Constantino é de fundamental importância, pois levou ao estabelecimento de um Império Cristão. Veyne destaca importância do fortalecimento do cristianismo para a legitimação política do novo imperador (VEYNE, 2010, p. 57).

A tradição cristã narra que, pouco antes de entrar em combate contra Maxêncio, na Ponte Mívia, próximo à Roma, o imperador “[...] rezava e fazia frequentes súplicas” (EUSEBIUS, 1902, p. 21). Segundo o seu amigo e biógrafo Eusébio de Cesareia (EUSEBIUS, 1902, p. 21), durante as preces do imperador, surgira um sinal divino no céu: as iniciais da palavra Cristo em grego (XPTO), acompanhada da inscrição hoc signus vinces (com esse sinal vencerás). Constantino teria mandado pintar o sinal nos escudos dos soldados, vencendo, assim, a batalha (CARLAN, 2013, p. 89).

Segundo o retórico cristão Lactâncio (LACTÂNCIO, 1954, p. 26), contemporâneo de Eusébio de Cesaréia, a visão de Constantino ocorrera durante um sonho, pouco antes do combate.

O novo imperador mandou cunhar uma série de moedas que lembravam a vitória de Constantino sobre seu rival, Maxêncio. Esta representação está presente no Arco do Triunfo, próximo ao Coliseu, em Roma.

Enquanto a construção é fixa e imóvel, a moeda, como documento alternativo e informativo', circula pelo vasto mundo romano, apresentando uma nova ideologia, uma mensagem política expressa no interior de suas imagens. Uma mensagem simbólica na qual a população, letrada ou não, saberia interpretar e identificar o governante, a religião defendida e praticada pelo soberano e a migração do poder para nova capital imperial.

Outros governantes, séculos mais tarde, copiaram o modelo constantiniano cunhando peças com a mesma legenda e iconografia, in hoc signvs vinces, como D. Manoel, o venturoso, de Portugal; D. Pedro I e D. Pedro II do Brasil.

De fato, Constantino tivera inicialmente uma religião solar, de tendência monoteísta, com o culto ao sol ou sol invictus, também representado em suas amoedações. Ele se considerava inspirado por um Deus Único, mas mal definido, e mantinha as funçóes de pontifex maximus, chefe sacerdotal ou chefe da religião, e mestre do paganismo. 
Funari define essa suposta conversão de Constantino como um jogo político. Segundo o autor:

[...] Assim o imperador Constantino concedeu aos cristãos, por meio do chamado Edito de Milão, em 313, liberdade de culto. Em seguida, esse mesmo imperador, procurou tirar vantagem e interveio nas questóes internas que dividiam os próprios cristãos e convocou um concílio, uma assembléia da qual participavam os principais padres cristãos. Nos Concílios foram discutidos as diretrizes básicas da doutrina cristã. Depois Constantino cuidou pessoalmente para que as determinaçóes do concílio fossem respeitadas, ou seja, passou a ter um controle muito maior dos cristãos e suas idéias. Antes de morrer, o imperador resolveu batizar-se também. (FUNARI, 2002, p. 131)

Dentro de sua política de contenção, Constantino escolheria como nova sede de governo uma cidade próxima às rotas comerciais que ligavam a Europa à Ásia, o mar Mediterrâneo ao mar Negro. Outro problema era a questão das fronteiras imperiais. Roma e o ocidente estavam mais vulneráveis às invasôes germânicas, enquanto que, no oriente, a distância mantinha uma certa segurança e a pressão política era menor.

Outra questão que Constantinopla ajudava a resolver era o perigo persa sassânida, império rival à Roma desde século III. A localidade de uma organização administrativa e militar, próxima aos persas, mantinha as fronteiras em constante vigilância.

\section{Uma nova cidade e uma nova capital}

Juridicamente, a cidade de Constantinopla era igual a Roma. A antiga boulế2 de Bizâncio, organização dos cidadãos da cidade, foi transformada em Senado, tendo um importante papel político até 1453 . A aprovação senatorial era indispensável para a legitimação do poder imperial e seus conselhos eram solicitados pelos imperadores.

O soberano recrutava os membros da alta administração e do consistório ${ }^{3}$. O primeiro dos senadores, membro de direito do consistório, era o "prefeito" da cidade e presidia o tribunal imperial na ausência do Imperador.

A população era dividida em quatro facções agrupadas duas a duas, os vermelhos e os verdes, os brancos e os azuis. Suas cores eram ostentadas e defendidas pelos condutores, os aurigas, nas corridas de carros no Hipódromo. Os azuis representavam a população ortodoxa dos bairros aristocráticos, as blaquernas. Os verdes, a população dos bairros pobres de Santa Eufêmia. Apesar da rivalidade dos grupos, às vezes se uniam para defender as suas liberdades contra o arbítrio do Imperador.

A nova capital, fundada em 330, batizada de Constantinopla em homenagem ao Imperador, unia as influências orientais, aliadas com a arte grega e a organização urbana de Roma.

Em pouco tempo, Constantinopla tornou-se a cidade mais cosmopolita do Império. Seus costumes, sua religião e cultura eram essencialmente gregos. Porém, consideravam-se romanos.

A palavra grego estava associada de maneira injuriosa ao paganismo. Os persas e, posteriormente, os árabes e os chineses também associaram os habitantes de Constantinopla a Roma, chamando-os de romanos. 
O termo bizantino começou a ser utilizado a partir do século XVII, quando os estudiosos o instituíram para fazer uma distinção entre o Império da Antiguidade, Romano do Oriente, e da Idade Média.

Estrategicamente Constantinopla estava bem localizada e resistiu a uma série de cercos, provando, assim, a boa visão militar de Constantino.

Para fortalecer ainda mais a força política da nova capital, o Imperador mandou cunhar uma série de moedas comemorativas. Essas cunhagens ocorreram entre os anos de 330 e 346 . Apesar da morte de Constantino, em 337, a exemplo de suas numárias póstumas (realizadas após a sua morte), seus herdeiros mantiveram a fabricação dessas peças até o ano de 341 .

\section{Moedas comemorativas: a fundação de Constantinopla}

As moedas aqui analisadas e interpretadas fazem parte da coleção do Museu Histórico Nacional, localizado na cidade do Rio de Janeiro. Apesar do acesso à Seção de Numismática e reserva técnica ser exclusivo aos funcionários e pesquisadores autorizados, já se encontra aberta para visitações a Exposição Permanente, desde dezembro de 2002. Essa exposição relata toda a História das Sociedades, bem como a relação Moeda/ História, desde a cunhagem da primeira moeda na Grécia (Lígia) até o Euro atual.

\section{Descrição do corpus}

Esses conjuntos de peças fazem parte do acervo numismático do Museu Histórico Nacional, no Rio de Janeiro, que possui o maior espólio de moedas e de medalhas da América Latina, com mais de 120 mil exemplares das mais variadas regióes.

Florenzano afirma que toda essa riqueza iconográfica, aliada a um trabalho de precisão milimétrico, teria outro objetivo além de uma simples troca comercial (FLORENZANO, 2002, p. 59).

Chartier destaca a importância da interpretação desses signos, chamada por ele de "signos do poder”.

Daí a necessidade de constituir séries homogêneas desses signos do poder: sejam as insígnias que distinguem o soberano dos outros homens (coroas, ceptros, vestes, selos, etc.), os monumentos que, ao identificarem o rei, identificam também o Estado, até mesmo a nação (as moedas, as armas, as cores), ou os programas que têm por objetivo representar simbolicamente o poder do Estado, como os emblemas, as medalhas, os programas arquitetônicos, os grandes ciclos de pintura... (CHARTIER, 1990, p. 220, grifos do autor).

Analisando a iconografia, podemos notar essa simbologia que demonstra os ritos comemorativos numa transferência do poder instituído pelo governante. Apesar de Constantino ser considerado o primeiro imperador cristão, os ícones pagãos encontram-se expressos nessas peças.

Esse conjunto de objetos foi cunhado a partir do ano de 330, continuando até 346, nove anos após a morte do Imperador (SEAR, 1988, p. 327). Teve como objetivo principal legitimar Constantinopla como a nova capital do Império, destinada a rivalizar com Roma, em vez de suplantá-la, como podemos observar em duas cunhagens do período. 
Na primeira delas, no anverso, notamos o busto da deusa Roma (representando a cidade), voltada à esquerda do observador, com capacete e o manto imperial. Circundada pela legenda VRBS. Portanto, Roma ainda era considerada a Cidade por excelência, aquela que todas as outras deveriam copiar e admirar. No reverso, sem legendas, no campo monetário, a loba amamentando os gêmeos Rômulo e Remo, numa alusão à fundação e origem da cidade. Acima dessas representações, duas estrelas. Algumas vêm acompanhadas de um banho de prata que, quando conservado, dá um realce artístico muito bonito.

\section{Figura 1 - Claudio Umpierre Carlan, maio de 2006. Acervo Museu Histórico Nacional, Rio de Janeiro.}

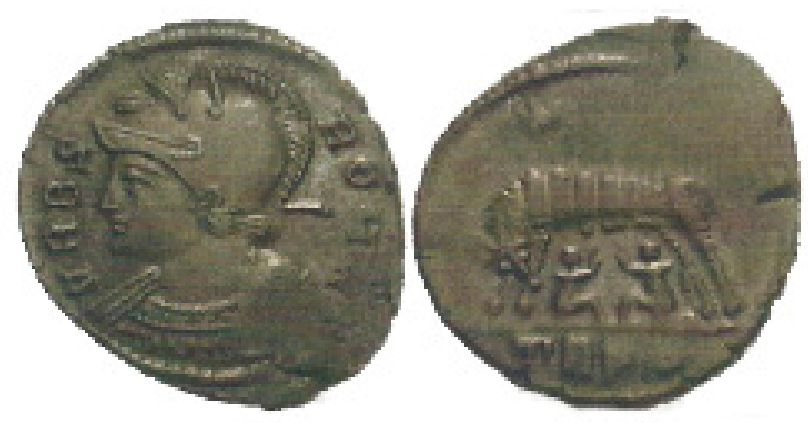

Fonte: (CARLAN, 2013, p. 43)

Existem dezenove peças com essa simbologia e foram cunhadas em Roma (seis), Constantinopla (cinco), Siscia (três), Trèves (duas), Císico (duas), e Aquileia (uma).

No outro exemplo, identificamos as seguintes alteraçóes: no anverso, a representação principal é da cidade de Constantinopla, circundada pela legenda Constantinopolis, seguindo o exemplo da peça citada anteriormente.

No reverso, trabalhamos com dois exemplos distintos. O primeiro deles traz a imagem da deusa Vitória, uma mulher alada, semelhante aos anjos cristãos, à esquerda do observador, sobre a proa de uma embarcação, utilizando como remo uma haste transversal e apoiando-se em um escudo.

Nesse universo simbólico, a Vitória guia o Império, como guia o navio, para um novo porto. O escudo é a proteção que a deusa transporta. Não podemos esquecer da importância marítima e estratégica da nova capital. No segundo, as alterações ocorrem no reverso, no qual a deusa Roma passa o cetro para a deusa Constantinopla, numa nítida troca das funçóes que circulam o âmbito do poder. $\mathrm{O}$ anverso permanece o mesmo.

Existem vinte moedas ${ }^{4}$, com essa iconografia, cunhadas nas seguintes cidades: Roma (cinco), Constantinopla (oito), Siscia (uma), Aquileia (uma), Antioquia (duas), Tessalônica (uma), Císico (duas), Trèves (uma). Além do banbo de prata, foram identificados alguns quinários, espécie de variação ou desvalorização da prata, muito comum em épocas inflacionárias.

Constantinopla sucedeu à antiga Bizâncio (fundada em 658 a.C.), por vontade de Constantino, que queria dar ao Império uma segunda capital, mais próxima das províncias ameaçadas pelos bárbaros dos Balcãs e pelos persas sassânidas. Durante todo o seu governo, Constantino dedicou-se a reformar profundamente o Império. Modificou a composição do senado, cujo conselho estava composto por seiscentos membros, aumentando para duzentos magistrados. Outra inovação foi a reforma da prefeitura do pretório: os comandantes da guarda imperial converteram-se em altos 
funcionários provinciais, dotados de amplos poderes civis, responsáveis por manterem a ordem pública e as finanças.

Apesar de não retornar à antiga forma de governo de que seu pai fez parte, Constantino limitou-se, dois anos antes de sua morte, a partilhar o governo dos territórios em cinco partes: três, as maiores, seriam entregues aos seus três filhos; as outras duas, a três de seus sobrinhos. $\mathrm{Ou}$ seja: coube ao filho mais velho, Constantino II, a Bretanha, a Gália e a Espanha; Constâncio II ficou com a rica parte oriental do Império que, desde 333, governava como César em Antioquia; o mais jovem, Constante, ficou com a Itália, a África e a Panônia. Os primos Flávio Júlio e Dalmário ficaram com os Balcãs, enquanto o primo Anibaliano ficou com a Ásia Menor.

Alguns autores chegaram a afirmar que Constantino teria a intenção de, bem antes de Merovíngios e Carolíngios, levar à aplicação um conceito patrimonial do Estado monárquico. Tal afirmação é discutida por Rémondon que, usando como base o testemunho numismático, afirma que Constantino havia pensado em seu filho mais velho, Constantino II, como herdeiro do império (RÉMONDON, 1973, p. 72).

Acreditamos que ele pretendia legar uma diferente organização política para aquele que o sucederia como coordenador e administrador. A morte não lhe deu tempo para isso. E se, realmente, como afirmou Rémondon, a ideia de Constantino era que o seu filho mais velho lhe sucedesse, por que a parte mais rica do império ficaria com o filho do meio, Constâncio? Não podemos esquecer que Constâncio II fora considerado pela posteridade como o mais eficiente administrador dentre os herdeiros do pai.

Com a morte de Constantino em 337, teve início um período de lutas internas pelo poder. Os numerosos meios-irmãos e sobrinhos de Constantino foram assassinados por políticos poderosos. Constâncio II defendia uma sucessão dinástica ordenada, livre da disputa entre os diversos ramos da família.

Essa ideia, que levou ao assassinato dos membros da família, foi defendida por Helena, mãe de Constantino, sendo provável que Constâncio II, o homem-forte do novo regime, tenha ordenado o massacre.

Deixou vivos, por razões sucessórias, (também como reféns) os jovens primos Constâncio Galo e Juliano. Mais tarde, ambos assumiram a função de César, primeiro Galo, depois Juliano.

A inovação desse século consistiu em discutir a ideia de uma linha sucessória direta e familiar: Constantino pensou nos seus sobrinhos e, Valentiniano I, centrado na defesa militar e das fronteiras, principalmente no Reno e Danúbio (invasões germânicas), associou-se a seu irmão Valente. Mesmo assim, sua rigorosa administração sofreu uma série de rebeliões na Ilíria e no norte da África.

A ideia familiar foi suficientemente forte para que, de uma dinastia à outra, se procurasse criar um laço, através do matrimônio. Valentiniano casa o filho, Graciano, então com dezesseis anos, com a neta de Constantino, com treze anos. E Teodósio, por sua vez, desposou a filha de Valentiniano (FUNARI; CARLAN, 2007, p. 23).

Os problemas administrativos e a questão sucessória levam Constâncio a nomear seu primo, Constâncio Galo, como César. A instabilidade de Galo e as intrigas palacianas levaram Galo a ser executado sob a acusação de traição. Seu irmão, Juliano, foi chamado à presença de Constâncio em Mediolanum (Milão). Em 355, foi nomeado César da parte ocidental do império e casou com a irmã do imperador. 
Nos anos seguintes, lutou contra as tribos germânicas que tentavam entrar em território do império. Nesta luta, distinguiu-se como estrategista, administrador e legislador. Recuperou Colonia Agripina (Colônia, Alemanha) em 356, derrotando os alamanos (em Argentoratum, na Batalha de Estrasburgo, França-Alemanha), assegurando a fronteira do Reno por outros cinquenta anos.

Lentamente, instalou-se nas vastas regióes imperiais um respeito ao imperador como governante supremo. Por este motivo, não podemos considerar completamente ineficazes os esforços das dinastias do século IV para regularizar a transmissão de poder. Uma herança que os reis medievais iriam aproveitar muito bem para legitimar e consolidar seus reinos.

Uma nova capital é efetivada, Constantinopla, antiga colônia grega de Bizâncio. A sua vida política, econômica e social, aos poucos vai se fortalecendo, rivalizando com a própria Roma. A ideia de Constantino era enfraquecer o incontrolável senado romano, estabelecer um eixo político -econômico mais próximo aos balcãs, protegendo a área contra uma futura invasão persa sassânida.

A dinastia sassânida (224-651) foi um constante tormento para Roma. Sapor I, o segundo rei persa dessa dinastia, já havia empreendido várias campanhas, muitas delas, bem sucedidas, contra as legióes romanas entre os anos de 241 e 250. Valeriano não foi capaz de fazer frente ao seu avanço e, em 259, foi capturado e feito prisioneiro, desastre sem precedentes nos anais romanos. Sapor celebrou com uma monumental escultura em relevo na parede de um penhasco em Nagsh-i Rustam, próximo a Persépolis.

Sapor $\mathrm{II}^{6}$ ainda muito jovem foi proclamado rei pelos nobres, após a deposição do seu irmão Adanarses. Seu outro irmão, Hormisda, fugiu para o lado dos romanos em $324 .{ }^{7}$ Durante sua longa menoridade, houve paz com Roma. Mas, em 336 a guerra novamente estoura, causada pelo controle da Armênia ${ }^{8}$, e, a partir daí, durante todo o período do seu reinado, houve guerra em quase todas as estações climáticas adequadas às campanhas, sendo que nenhum dos lados foi completamente vitorioso.

As bases das reformas de Constantino foram mantidas pelos seus sucessores. A aliança com a Igreja, legítima herdeira de Cristo e do Império, tornou-se cada vez mais forte. Com isso, estava formado uma das bases do pensamento político medieval: o Sumo pontífice, bispo de Roma, e as dinastias bárbaras-germânicas.

Construída, ou melhor, reconstruída, entre os anos de 324 e 336, a Nova Roma foi inaugurada em onze de maio de 330. Capital política pela presença do imperador, a partir do final do século IV; religiosa como sede do patriarcado do Oriente; intelectual graças à sua universidade, fundada em 330; econômica por sua posição na encruzilhada das grandes rotas comerciais, Constantinopla era protegida por um duplo cinturão militar formado pelos muros de Constantino (século IV) e de Teodósio (século V), completada, nas três faces marítimas por importantes fortificaçôes que a preservaram de todos os assaltos até o século XIII.

\section{Considerações finais}

As moedas configuravam significados e mensagens do emissor (imperador, membros de sua família ou pessoas que circulavam próximas ao poder) para seus governados. Continham símbolos que deveriam ser entendidos ou decifrados pelo receptor. Tal como os símbolos urbanos, que representavam a cidade ou algum habitante importante, ou as insígnias dos imperadores romanos 
que vão reaparecer durante a Idade Média, no governo de Frederico II (1194-1250), imperador do Santo Império Romano-Germânico.

Não podemos esquecer de que a numismática deve ser definida como uma disciplina científica, pois através dela podem ser estudados muitos aspectos de uma determinada sociedade (FRÉRE, 1984, p. 11). Ou, como definiu Vasconcelos no final do século XIX:

[...] ciência que tem por objetivo o estudo morfológico e interpretativo das moedas; morfológico porque as moedas hão de apreciar-se quanto ao seu metal, ao seu aspecto, a suas figuras, sinais, letreiros; interpretativo porque se tem de dar a razão de tudo o que o estudo morfológico revelou nas moedas. É como que um estudo anatômico e fisiológico, ou estático e dinâmico, ou da forma e da função (VASCONCELOS, 1895, Vol. 1, p. 301).

Dentro desse ponto de vista, temos que ter cuidado para não cometermos o que Bourdieu chama de "etnocentrismo inverso", ou seja, atribuir a todas as sociedades, mesmo as consideradas mais "primitivas”, formas de capital cultural que só podem se constituir a um nível determinado do desenvolvimento da divisão do trabalho (BOURDIEU; DARBEL, 2003, p. 41).

As moedas, medalhas e sinetes são documentos de alta valia para os estudos arqueológicos e históricos, prestando serviço a egiptologia, assiriologia, à história das civilizações da Hélade, do Latium, da Etrúria, da Judeia, da Síria, da Armênia (VIEIRA, 1995, p. 105).

Através das moedas e medalhas é possível estabelecer não apenas datações precisas, mas escrever a história do poder temporal dos papas, reis, imperadores e de todos aqueles que circundam a orla do poder.

Devemos pensar a moeda na Antiguidade com uma função específica dentro daquela realidade. Função política, social, administrativa, militar, religiosa e econômica. Não podemos nos restringir apenas à economia. Até hoje, principalmente na Europa e Estados Unidos, a moeda ainda mantém o caráter propagandista. A responsabilidade pelas ideias restringe-se ao autor.

\section{Referências}

BASTIEN, Pierre; HUVELIN, Hélène. Trouvaille de Folles de la Période Constantienne. Belgique: Éditions Cultura Wetteren, 1969, p. 307-317.

BOURDIEU, Pierre; DARBEL, Alain. O Amor pela Arte: os museus de arte da Europa e seu público. Tradução de Guilherme João de Freitas Teixeira. São Paulo: Editora da Universidade de São Paulo: Zouk, 2003.

BRUUN, Patrick. Studies in Constantinian Numismatics. Papers from 1954 to 1988 . Acta Instituti Romani Finlandiae. v. 12. Rome: Illus, 1991.

CALLY, Jean Pierre; BARRANDON, Jean Noel. L'Inflazione nel IV secolo. Società romane e Impero tardoantico. V. I. Instituzioni, ceti, economie. Rome; Bari: Editori Laterza, 1986, p. 295-361.

CARLAN, Claudio Umpierre. As Fortificações e Constâncio II. In: Revista do Clube da Medalha. ano XII. n. 24. Rio de Janeiro: Casa da Moeda do Brasil, 2003.

CARLAN, Claudio Umpierre. Moeda e poder em Roma, um mundo em transformação. São Paulo: Annablume, 2013.

CARVALHO, Margarida Maria de. Gregório de Nazianzo e a Polêmica em Torno da Restauração Pagã de Juliano. In: SILVA, Gilvan Ventura; MENDES, Norma Musco (org.). Repensando o Império Romano. Perspectiva Socioeconômica, Política e Cultural. Rio de Janeiro: Mauad Editora, 2006. 
CATÁLOGO LOS AVREOS ROMANOS 196 A.C - 335 D.C. Por Xavier Calico, miembro de La Internacional Associatión of Professional Numismatics. Barcelona, 2002, p. 321.

CHARTIER, Roger. A História Cultural: entre práticas e representações. Tradução de Maria Manuela Galhardo. Lisboa: DIFEL, 1990.

DEPEYROT, Georges. Economie et Numismatique. Paris: Errance, 1987, p. 284-491.

EUSEBIUS PAMPHILI, Bispo de Cesaréa. De Vita Constantini.v. 7. Lib. I. Leipzig: Texto da Edição I. A. Heikel, 1902.

FLORENZANO, Maria Beatriz Borba. O “Outro lado da moeda na Grécia Antiga”. In: Livro do Seminário Internacional O Outro Lado da Moeda. Rio de Janeiro: Museu Histórico Nacional, 2002.

FRÈRE, Hubert. Numismática. Uma Introdução aos Métodos e à Classificação. Tradução e adaptação de Alain Costilhes e Maria Beatriz Florenzano. São Paulo: Sociedade Numismática Brasileira, 1984.

FUNARI, Pedro Paulo Abreu; CARLAN, Claudio Umpierre. Arqueologia Clássica e Numismática. Coleção Textos Didáticos n. 62. Campinas: IFCH / UNICAMP, 2007.

FUNARI, Pedro Paulo Abreu. Grécia e Roma: vida pública e vida privada. Cultura, pensamento e mitologia, amor e sexualidade. 2. ed. São Paulo: Contexto, 2002.

LACTÂNCIO. De Mortibus Persecutorum. Paris: Ed. J. Moreau, 1954.

MARQUES, Mario Gomes. Introdução à Numismática. Lisboa: Publicações Dom Quixote, 1982

MARSHALL, Francisco. Ícone, Ideologia e Cultura. ljuí: Leitura em Revista, 2003.

MOEDAS DO IMPERADOR CONSTANTINO I, o grande. Acervo do Museu Histórico Nacional, Rio de Janeiro, Medalheiro 3, gaveta 19, lâmina 3, fotografadas em março de 2005.

MOMIGLIANO, Arnaldo. Ensayos de Historiografia Antigua y Moderna. México: FCE, 1993.

MUSEU NACIONAL D`ARTE DE CATALUNYA. Guia del Gabinet Numismàtic de Catalunya. Dirigida por Marta Campo. Barcelona: MNAC, 2007.

NIETO SORIA, Jose Manuel. Ceremonias de La Realeza. Propaganda y Legitimacion en La Castilla Trastámara. Madrid: Editorial Nerea, 1993.

RÉMONDON, Roger. La Crisis del Imperio Romano. De Marco Aurelio a Anastasio. 2. ed. Barcelona: Editorial Labor, 1973.

SEAR, David R. Roman Coins ande Their Values. $4^{\text {th }}$ Revised Edition. London: Seaby Publications Ltd, 1988, p. 327

THE ROMAN IMPERIAL COINAGE. Edited by Harold Mattingly, C.H.V. Sutherland, R.A.G. Carson. V. VIII. London: Spink and Sons Ltda, 1983.

VASCONCELOS, J. Leite de. Objecto da Numismática. In: $O$ archeologo português. v. 1. Lisboa: Imprensa Nacional, 1895.

VEYNE, Paul. El Sueño de Constantino. Madrid: Gredos, 2010.

VIEIRA, Rejane Maria Lobo. Uma grande coleção de moedas no Museu Histórico Nacional? In: Anais do Museu Histórico Nacional. v. 27, Rio de Janeiro: Museu Histórico Nacional, 1995.

ZÓSIME. Histoire Nouvelle. III. 18. ed. Paris: F. Paschoud, 1979.

DATA de Recebimento : 09/05/2018

DATA de Aprovação : 12/10/2018

\section{Notas}

1. A moeda, como documento informativo, possui uma natureza diferente do texto impresso. 
Cidade e Moeda na História: Constantino e Constantinopla, uma nova capital...

2. Assembleia de cidadãos, encarregados da legislação e deliberação nas cidades gregas.

3. Reunião de Cardeais para auxiliar o Papa em suas decisões.

4. O inventário da coleção encontra-se no Museu Histórico Nacional, no Rio de Janeiro.

5. Assim chamada em homenagem a Sassan, antepassado lendário do primeiro rei Aldachir I.

6. Neto de Narses ou Narseu, derrotado pelo tetrarca Galério, em 298. Quando o exército romano marchou sobre Ctesifonte, capital persa, Narses foi obrigado a implorar pela paz e a liberação de sua família.

7. Durante o reinado de Constâncio II, foi comandante de cavalaria, acompanhado-o a Roma em 357. Foi general durante a expedição de Juliano em 363.

8. Sapor I e Narses também entraram em guerra contra Roma pelo mesmo motivo. 